\title{
Система корпоративного управления, дискреционная власть менеджмента и инвестиции компаний в НИОКР: эмпирическое исследование на примере Китая
}

\author{
Джинг ДОНГ, ${ }^{26}$ Минг Ю $^{27}$ \\ Перевод Пирогова Н.К. ${ }^{28}$
}

В данной работе мы изучили влияние факторов корпоративного управления на инвестиции компаний в инновачионные проекты (НИОКР). Изученные факторы включают независимых директоров, структуру институцчиональных инвесторов, дискреционную власть менеджмента, долю государственной собственности, а также долю собственности, находящейся в руках менеджмента. Тестирование данных гипотез проводилось с использованием эконометрического инструментария на основе данных о компаниях, акции которых торгуются на фондовом рынке Китая. Результаты говорят о наличии значимой отрицательной коррелящии между дискрециионой властью менеджмента и уровнем инвестиций в НИОКР. Увеличение количества независимых директоров приводит $\kappa$ росту инвестиций в НИОКР. Однако не было обнаружено значимого влияния концентрации собственности и доли государственной собственности на инвестиции $в$ НИОКР.

\section{Введение}

Целый ряд академических исследователей пытались изучать факторы, влияющие на интенсивность инвестиций в инновационные проекты. Часть ученых пришла к выводу, что основными факторами являются отраслевая среда, позиционирование компаний, а также отношение менеджмента к НИОКР. Другие исследователи обнаружили, что важную роль играют факторы корпоративного управления, в частности практика проведения собраний советов директоров и структура акционерной собственности.

В общем можно сказать, что инвестиции в НИОКР характеризуются долгим сроком реализации и низкой вероятностью получения положительного результата. Если инновационный проект доказал свою состоятельность, можно ожидать высоких финансовых результатов от коммерческой реализации, но риск тем не менее остается высоким. Таким образом, инвестиции в НИОКР ассоциируются с высокой доходностью и высоким риском. Реализация инновационной стратегии неизбежно проводится на фоне конфликтов между менеджерами и акционерами, которые возникают из-за несоответствия их интересов.

Большинство исследователей принимают в качестве предпосылки утверждение о том, что менеджмент компаний обычно не любит инвестировать в НИОКР. Компенсация руководящего состава обычно зависит от финансовых показателей деятельности компании. Если высокорискованные инвестиции в НИОКР оказываются неудачными, развивается кризис доверия и повышается профессиональный риск для менеджмента, который очень сложно диверсифицировать [Альчиан, Демзец, 1972]. Байсингер и Хоскиссон [1989] обнаружили, что система компенсации топ-менеджмента обычно увязана с финансовыми показателями эффективности (часто - с показателем доходности инвестиций). Учитывая, что инвестиции в НИОКР будут отрицательно влиять на текущую доходность, менеджмент

\footnotetext{
${ }^{26}$ Профессор, организационный менеджмент и стратегия, Шанхайский университет экономики и финансов, Китай.

${ }^{27}$ Шанхайское подразделение, Индустриальный и коммерческий банк Китая.

${ }^{28}$ Старший преподаватель кафедры экономики и финансов фирмы ГУ-ВШЭ.
} 
компаний отдаст предпочтение краткосрочным проектам, доход от которых может быстро проявиться в финансовой отчетности. Такой подход особенно характерен для менеджеров старшего возраста. Молодые управленцы обычно более спокойно относятся к высокорискованным проектам [Баркер, Мюллер, 2002].

Исследования по выявлению влияния практики работы совета директоров на инвестиции в НИОКР обычно концентрируются на анализе независимых директоров. Независимые директора не занимают внутрикорпоративных должностей и не получают компенсации от компании. Обычно предполагается, что независимые директора анализируют решение компании более честно и объективно, они должны исследовать эффективность менеджмента, а также добиваться одинаковой информированности менеджмента и акционеров. Первоначально предполагалось, что независимые директора могут помочь оптимизировать инвестиции в НИОКР благодаря своему долгосрочному горизонту планирования. Иначе говоря, доля независимых директоров в совете директоров должна иметь положительную корреляцию с объемом инвестиций в НИОКР [Байсингер, Хоскиссон, 1990]. Однако эмпирические исследования выявили наличие противоположной связи. Было обнаружено, что наличие независимых директоров приводит к уменьшению инвестиций в инновационные проекты. В качестве объяснения такой взаимосвязи была предложена информационная ограниченность независимого директора. Внешнему директору обычно сложно получить внутреннюю и детальную информацию внутри компании. Такому директору обычно доступна общая финансовая информация, без деталей $\quad$ и подробностей. Таким образом, независимым директорам обычно приходится работать с обобщенной финансовой информацией [Хилл, Снелл, 1988; Хоскиссон, Хитт, Джонсон, 2002].

Все акционеры могут быть разделены на две основные группы - институциональные и индивидуальные инвесторы. По сравнению с институциональными инвесторами индивидуальные обычно контролируют небольшую долю акционерного капитала и имеют меньшее влияние на компанию. Большинство исследователей концентрируются на роли институциональных инвесторов. К настоящему времени большая часть исследований проводилась на выборке из американских компаний, а институциональные инвесторы ассоциируются в первую очередь с инвестиционными и фондовыми компаниями. Грейвз [1988] пишет, что такие финансовые организации обычно отрицательно относятся к риску, предпочитают краткосрочные проекты с коротким сроком окупаемости и стараются не инвестировать в инновационные проекты. Тем не менее часть исследователей полагают, что финансовые организации обладают достаточным потенциалом для диверсификации собственных инвестиций и должны способствовать повышению инвестиций в НИОКР. Их позиция состоит в том, что институциональный инвестор должен способствовать развитию инновационных процессов в компании, а не ограничивать их. Часть исследований подтверждает данную позицию [Байсингер, Тюрк, Косник, 1991; Хилл, Хансен, 1991; Кочар, Дэвид, 1996].

Часть исследователей считает, что указанный выше конфликт во взглядах на институциональных инвесторов легко объясняется различием в выборе видов институциональных инвесторов. Дэвид, Хитт и Джимено [2001] обнаружили, что такие публичные фондовые инвесторы, как пенсионные фонды, обычно ожидают от компаний реализации политики высоких инвестиций в НИОКР. Они предпочитают подождать и получить долгосрочный доход, а не сомнительную краткосрочную доходность, которой возможно добиться и путем непрекращающейся купли-продажи. Хоскиссон, Хитт и Джонсон [2002] отмечают, что пенсионные (общедоступные) фонды обычно стимулируют инвестиции в НИОКР и способствуют разработке новой продукции.

\section{1. Теории и гипотезы}

Как мы уже упоминали, больше всего исследований по анализу взаимосвязи системы корпоративного управления и инвестиций в инновационные проекты проводилось на 
выборке из американских компаний. Какие же зависимости между корпоративным управлением и инвестициями в НИКОР можно получить, если в качестве примера взять Китай? Китайские компании функционируют в совершенно других условиях, а их системы корпоративного управления сильно отличаются от практики, наблюдаемой в США. В данном исследовании мы проводим попытку изучить корреляцию между инвестициями в НИОКР и факторами корпоративного управления в Китае, которые включают дискреционную власть менеджмента, структуру собственности и практику работы совета директоров.

\section{1. Дискреционная власть менеджмента}

Дискреционная власть менеджмента характеризует возможности руководства компании влиять на корпоративные решения. Обычно выделяют три определяющих фактора - структуру корпоративного управления, управленческую структуру, а также персональные характеристики менеджера. Мы согласны с другими исследователями [Байсингер, Хоскиссон, 1989; Хоскиссон, Хитт, Джонсон, 2002 и др.] в том, что в менеджмент в общем должен негативно относиться к интенсификации инвестиций в инновационные проекты, предпочитая сокращать расходы на НИОКР и улучшать краткосрочную финансовую эффективность деятельности компании. Учитывая данную предпосылку, можно сказать, что увеличение дискреционной власти менеджмента может позволить ему уменьшить корпоративные инвестиции в НИОКР до желаемого уровня.

Гипотеза 1. Дискреционная власть менеджмента отрицательно коррелирует с инвестициями компании в НИОКР. Чем больше дискреционная власть менеджмента, тем меньше уровень инвестиций в инновационные проекты.

\section{2. Система корпоративного управления}

Принимая во внимание особенности политической, социальной и экономической среды в Китае, мы сформулировали следующие гипотезы о взаимосвязи факторов корпоративного управления с инвестициями компаний в НИОКР.

Доля государственной собственности. В настоящий момент множество крупных корпораций в Китае все так же контролируется государством, которое имеет большую долю собственности. Компании с высокой долей государственной собственности в акционерном капитале обычно занимают монополистическое положение в отрасли. Можно предположить, что компания, являющаяся монополистом, вряд ли станет проявлять высокую активность в области улучшения собственной эффективности и не будет интенсивно инвестировать в инновационные проекты.

Гипотеза 2. Доля государственной собственности характеризуется отрицательной корреляцией с инвестищиями в НИОКР.

Доля собственности в руках менеджмента. Если доля акционерного капитала, контролируемого руководством компании, растет, менеджеры перестают быть просто наемными профессионалами - они все больше становятся собственниками. Агентский конфликт между менеджментом и другими акционерами уменьшается, что в результате должно привести к увеличению инвестиций в НИОКР, основной целью которых является долгосрочное укрепление конкурентного положения компании на рынке.

Гипотеза 3. Доля собственности в руках менеджмента положительно связана с инвестищиями в НИОКР.

Степень концентрации собственности. По мере увеличения количества акций в руках нескольких акционеров (обычно институциональных инвесторов) их возможности контроля возрастают. Это позволяет крупным акционерам вмешиваться в операционную деятельность компании и, в частности, повышать уровень инвестиций в инновационные проекты. 
Гипотеза 4. Концентрация собственности положительно коррелирует $c$ инвестищиями в НИОКР. Чем выше конщентрация собственности, тем выше инвестищии в НИОКР.

Внешние независимые директора. Основным место работы большинства внешних независимых директоров в Китае является либо университет, либо исследовательская организация. Принимая во внимание особенности данной группы специалистов, мы считаем, что независимые директора будут способствовать увеличению инвестиций в инновационные проекты компаний.

Гипотеза 5. Доля внешних независимых директоров в совете директоров имеет положительную корреляцию с инвестищиями компании в НИОКР.

\section{2. Данные и методы исследования}

\section{1. Методы исследования}

Целью нашего эмпирического исследования является анализ влияния факторов корпоративного управления (дискреционной власти менеджмента, доли государственной собственности, доли собственности в руках менеджмента, концентрации собственности, внешних независимых директоров) на инвестиции компаний в инновационные проекты. В рамках данного проекта мы используем стандартный инструментарий регрессионного анализа. Мы проведем тестирование пяти обозначенных гипотез. Мы используем программный пакет SPSS версии 14.0.

\section{2. Выборка}

Выборка включает в себя производственные компании, акции которых торгуются на Шанхайской и Шеньдженьской фондовых биржах в Китае. Мы считаем, что в производственных компаниях, по сравнению с компаниями из сферы услуг, должно наблюдаться большее количество инициатив в области реализации инновационных проектов. Данные о компаниях основаны на отчетности об их деятельности в 2005 г. Компании, соответствующие признаку red-ST, SST и *ST, в выборку не включались. Всего была собрана информация о 226 компаниях. В связи с недоступностью информации результирующая выборка включила в себя 78 наблюдений. Отраслевое распределение выборки представлено в таблице 1.

Таблица 1. Отраслевое распределение

\begin{tabular}{|l|l|l|l|l|l|}
\hline Производственная & Электронная & Химическая & Медицинская & Автомобльная & Всего \\
\hline 20 & $\mathbf{3 2}$ & $\mathbf{8}$ & $\mathbf{1 2}$ & $\mathbf{6}$ & $\mathbf{7 8}$ \\
\hline
\end{tabular}

Собранные данные включают в себя: выручку от основной деятельности, инвестиции в НИОКР, задействованный капитал (flowing current), количество директоров в совете директоров, количество внешних независимых директоров, компенсацию менеджмента, долю государственной собственности, долю собственности под контролем 10 крупнейших акционеров, долю собственности, находящейся в руках менеджмента, и другую информацию, представленную в таблице 2. 
Таблица 2. Статистические характеристики выборки

\begin{tabular}{|l|r|r|r|r|r|}
\hline & $\mathrm{N}$ & Minimum & Maximum & \multicolumn{1}{c|}{ Mean } & Std. Deviation \\
\hline prime operating revenue & 78 & 61.38 & 51675.61 & 3829.40 & 7784.93 \\
R\&D investment & 78 & .14 & 262.27 & 14.95 & 34.84 \\
R\&D investment intensity & 78 & $.01 \%$ & $3.57 \%$ & $.64 \%$ & $.80 \%$ \\
flowing current & 78 & 0 & 2853 & 248.91 & 445.723 \\
employee & 78 & 112 & 65506 & 4653.68 & 8304.627 \\
director & 78 & 0 & 19 & 9.81 & 2.370 \\
Independent outside director & 78 & 0 & 7 & 3.42 & .859 \\
Share held by the state & 78 & $.00 \%$ & $84.98 \%$ & $37.26 \%$ & $24.99 \%$ \\
Share held by manager & 78 & $.00 \%$ & $70.26 \%$ & $1.59 \%$ & $8.29 \%$ \\
Degree of share concentration & 78 & $15.06 \%$ & $93.71 \%$ & $62.09 \%$ & $13.39 \%$ \\
\hline
\end{tabular}

\section{3. Показатели}

Интенсивность инвестиций В НИОКР. В качестве показателя интенсивности инвестиций в НИОКР мы используем отношение инвестиций в НИОКР к выручке от основной деятельности.

Индекс дискреционной власти менеджмента. В соответствии с исследованием Ли [2002], дискреционная власть менеджеров может быть приблизительно измерена с помощью эффекта должностной власти, компенсационного эффекта и эффекта операционного контроля.

1. Индекс должностной власти связан в первую очередь с самой должностью и предоставляемыми ею полномочиями. В данной работе он определяется обратным значением количества топ-менеджеров в компании. Чем больше данное значение, тем выше концентрация должностной власти и соответственно дискреционные возможности менеджмента.

2. Компенсационный индекс является показателем, определяющим уровень власти менеджмента путем учета уровня его заработной платы. Мы в исследовании используем отношение размера компенсации генерального директора к наименьшей заработной плате в команде топ-менеджеров. Чем больше данный относительный показатель, тем выше относительная значимость генерального директора в компании и тем больше может быть сконцентрировано власти в его/ее руках.

3. Эффект операционного контроля определяется объемом финансовых ресурсов, который находится под контролем генерального директора. В данной работе мы используем отношение значения оборотного капитала к доходу бизнеса.

Индекс дискреционной власти менеджмента определяется усредненным значением стандартизированных индекса должностной власти, компенсационного индекса, а также индекса операционного контроля.

Степень концентрации акционерного контроля. Степень концентрации акционерного контроля определяется долей акций, находящихся в руках 10 крупнейших собственников компании.

Доля государственной собственности определяется процентным значением акций, находящихся в руках государства.

Доля собственности в руках менеджмента определяется процентом акций, находящихся в собственности топ-менеджеров компании.

Показатель независимые директора определяется количеством внешних директоров в совете директоров компании. 


\section{4. Обработка данных перед тестированием}

Перед проведением регрессионных тестов нам необходимо убедиться в том, что все переменные имеют нормальное распределение и между ними отсутствует мультиколлинеарность. После проведения тестов на нормальность распределения мы определили, что значение теста по переменной «доля собственности в руках менеджмента» (SHBM) составило менее 0,05 , что означает ненормальность распределения. В связи с этим мы прологарифмировали данный показатель - $\log (\mathrm{SHBM}),-$ и результат теста улучшился до требуемого уровня. В таблице 3 представлены результаты тестов на нормальность распределения всех переменных. В тестах на корреляцию мы не обнаружили значимой мультиколлинеарности между переменными.

Таблица 3. Скорректированный тест на нормальность распределения

One-Sample Kolmogorov-Smirnov Test

\begin{tabular}{|c|c|c|c|c|c|}
\hline & $\begin{array}{c}\text { Discretionary } \\
\text { power index o } \\
\text { managers }\end{array}$ & $\begin{array}{c}\text { Share } \\
\text { held by the } \\
\text { state }\end{array}$ & $\begin{array}{c}\text { ndependent } \\
\text { outside } \\
\text { director }\end{array}$ & $\begin{array}{c}\log \\
(\mathrm{SHBM})\end{array}$ & $\begin{array}{c}\text { Degree of } \\
\text { share } \\
\text { concentration }\end{array}$ \\
\hline$\overline{\mathrm{N}}$ & 78 & 78 & 78 & 78 & 78 \\
\hline Normal Paramelęs Mean & .4245 & $37.26 \%$ & $34.44 \%$ & -10.73 & $62.09 \%$ \\
\hline Std. Deviation & .1579 & $24.99 \%$ & $5.27 \%$ & 4.19 & $13.39 \%$ \\
\hline Most Extreme & .097 & .095 & .178 & .183 & .077 \\
\hline Differences & .097 & .095 & .178 & .183 & .077 \\
\hline Negative & -.088 & -.091 & -.174 & -.099 & -.057 \\
\hline Kolmogorov-Smirnov Z & .856 & .841 & 1.573 & 1.616 & .677 \\
\hline Asymp. Sig. (2-tailed) & .456 & .479 & .014 & .011 & .750 \\
\hline
\end{tabular}

a. Test distribution is Normal.

b. Calculated from data.

\section{3. Результаты}

\section{1. Дискреционная власть менеджмента и корпоративные инвестиции в НИОКР}

Мы использовали инструментарий линейной регрессии для тестирования гипотезы о наличии корреляции между дискреционной властью менеджмента и корпоративными инвестициями в НИОКР. Уровень значимости составил 0,001, что означает высокую значимость полученных результатов. Скорректированный $\mathrm{R}^{2}$ составил 0,141 . Иначе говоря, дискреционная власть менеджмента на $14,1 \%$ определяет изменение инвестиций компании в НИОКР. Значение коэффициента регрессии отрицательное, что говорит об отрицательной корреляции инвестиций в НИОКР и дискреционной власти менеджмента. Таким образом, первая гипотеза статистически подтверждается. Дискреционная власть менеджмента отрицательно связана с инвестициями в НИОКР. Чем больше дискреционная власть менеджмента, тем меньше инвестиции компании в НИОКР.

Таблица 4. Регрессия дискреционной власти менеджмента и инвестиций в НИОКР Model Summary and Parameter Estimates

Dependent Variable: R\&D investment intensity

\begin{tabular}{|l|r|r|r|r|r|r|r|}
\hline \multirow{2}{*}{ Equation } & \multicolumn{5}{|c|}{ Model Summary } & \multicolumn{2}{c|}{ Parameter Estimates } \\
\cline { 2 - 9 } & R Square & $\mathrm{F}$ & $\mathrm{df1}$ & $\mathrm{df2}$ & Sig. & Constant & b1 \\
\hline Linear & .141 & 12.426 & 1 & 76 & .001 & .010 & -.011 \\
\hline
\end{tabular}

The independent variable is Discretionary power index of managers. 


\section{2. Система корпоративного управления и инвестиции в НИОКР}

\section{Доля государственной собственности}

Из приведенной ниже диаграммы мы можем видеть, что связь между долей государственной собственности и инвестициями в НИОКР практически отсутствует. Значимого уровня корреляции не наблюдается. Соответственно мы отвергаем вторую гипотезу.

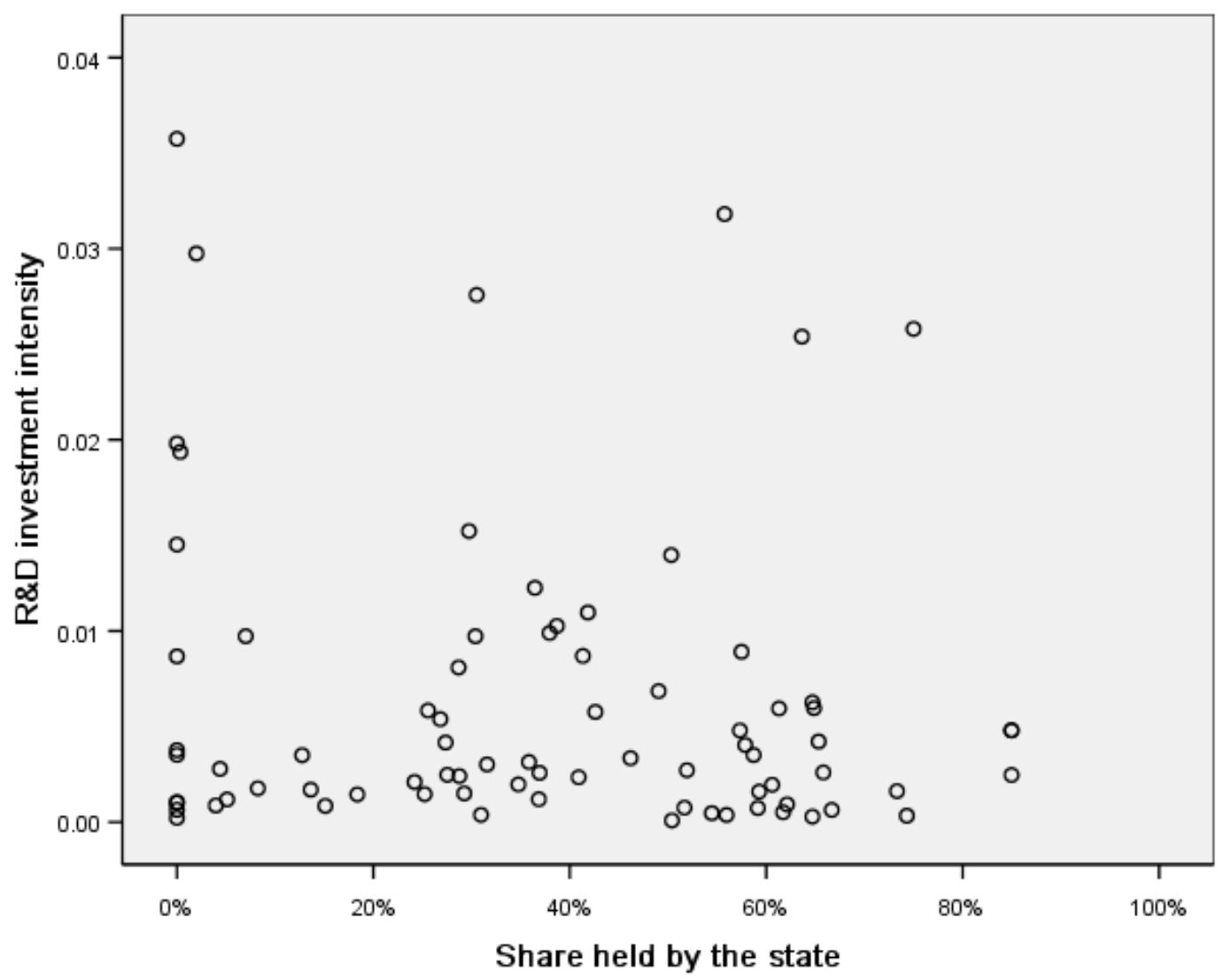

\section{Диаграмма 1. Зависимость инвестиций в НИОКР от доли государственной собственности}

\section{Доля собственности в руках менеджмента}

Из диаграммы зависимости инвестиций в НИОКР от доли собственности в руках менеджмента явствует, что все наблюдения располагаются по кривой. В связи с этим мы использовали нелинейный регрессионный анализ и обнаружили наличие значимой квадратичной зависимости между переменными. Уровень значимости оказался достаточно высоким и составил 0,004. Значение скорректированного $\mathrm{R}^{2}$ составило 0,138 . Это означает, что функция определяет до $13,8 \%$ всех изменений инвестиций компании в НИОКР. Произведение коэффициентов регрессий отрицательное. Это можно проинтерпретировать следующим образом: по мере увеличения доли собственности в руках менеджмента инвестиции в НИОКР сначала уменьшаются, а потом увеличиваются, что соответствует квадратичному виду функции. Этот результат не полностью подтверждает нашу третью гипотезу. Мы объясняем этот факт следующим образом: когда менеджмент владеет лишь небольшой долей собственности, курсы акций и их стоимость определяют небольшую долю доходов менеджмента. У руководства компании практически отсутствует мотивация влиять на цену акций путем реализации краткосрочных проектов. По мере увеличения доли собственности, подконтрольной менеджменту, курсы акций начинают оказывать все большее влияние на доходы руководства компании. Это приводит к тому, что менеджмент 
компании становится лично заинтересованным в повышении цены акции и начинает реализовывать краткосрочные проекты, которые могут положительно отразиться на финансовых результатах деятельности компании. Когда доля собственности руководства становится значительной, акционерам-менеджерам уже сложно избавиться от своих акций за короткий промежуток времени - из-за наличия законодательных ограничений. Таким образом, менеджмент начинает отдавать предпочтение долгосрочным инвестициям в НИОКР с целью увеличения конкурентоспособности компании.

Таблица 5. Регрессия инвестиций в НИОКР от доли собственности в руках менеджмента

\section{Model Summary and Parameter Estimates}

Dependent Variable: R\&D investment intensity

\begin{tabular}{|c|r|r|r|r|r|r|r|r|}
\hline \multirow{2}{*}{ Equation } & \multicolumn{5}{|c|}{ Model Summary } & \multicolumn{3}{c|}{ Parameter Estimates } \\
\cline { 2 - 9 } & R Square & $\mathrm{F}$ & $\mathrm{df1}$ & $\mathrm{df2}$ & $\mathrm{S}$ Sig. & Constant & $\mathrm{b} 1$ & $\mathrm{~b} 2$ \\
\hline Quadratic & .138 & 5.994 & 2 & 75 & .004 & .021 & .004 & .000 \\
\hline
\end{tabular}

The independent variable is log (SHBM).

\section{Степень концентрации собственности}

Из представленной ниже диаграммы можно заметить, что значимая связь между инвестициями в НИОКР и концентрацией собственности отсутствует. Таким образом, наша четвертая гипотеза не подтверждается.

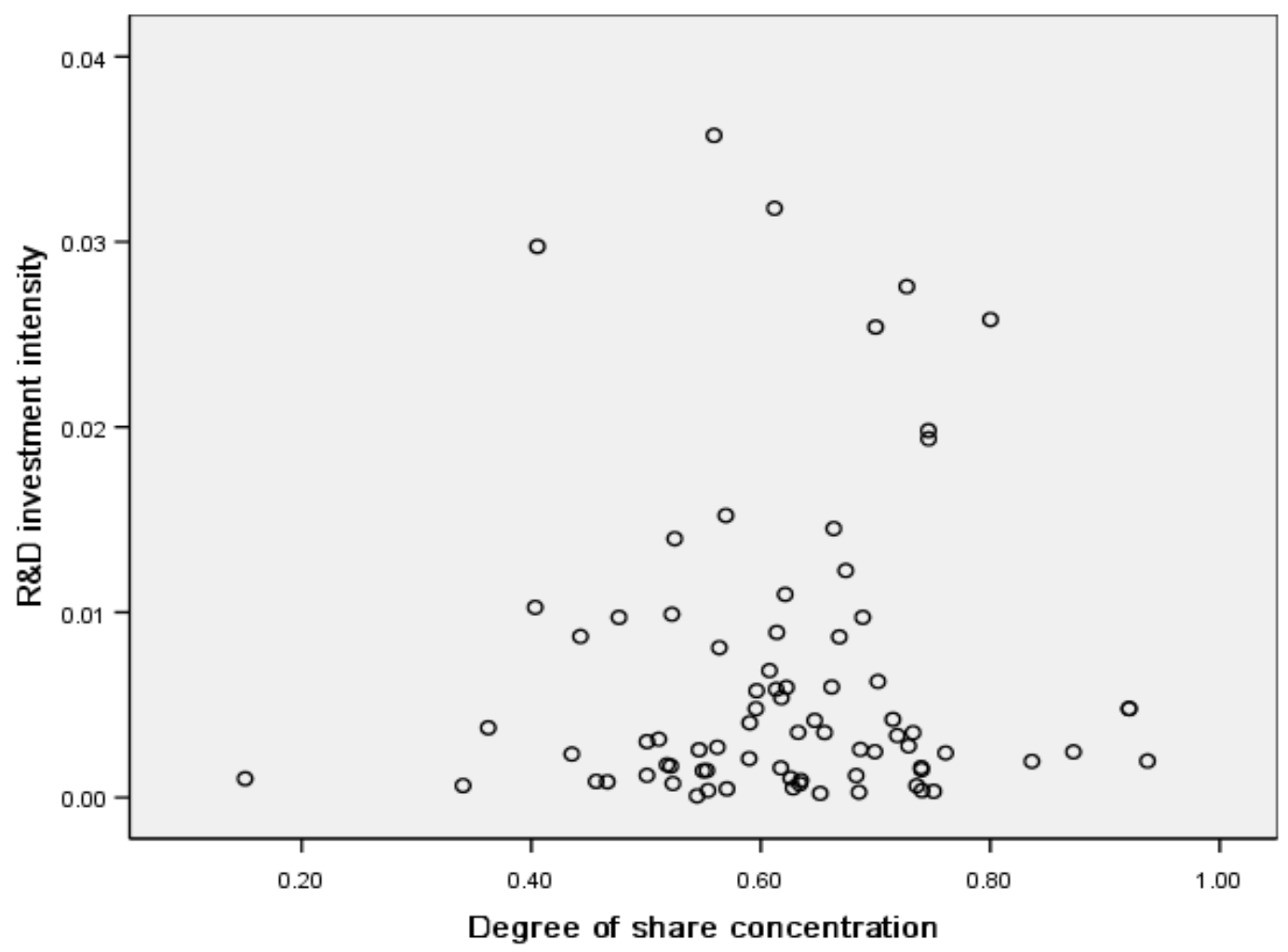

\section{Диаграмма 2. Зависимость инвестиций в НИОКР от концентрации собственности}

\section{Независимые директора}

Мы не обнаружили какой-либо корреляции между показателями инвестиции в НИОКР и долей независимых внешних директоров в совете директоров компании. Однако была обнаружена значимая корреляция между количеством независимых директоров и инвестициями компании в НИОКР. Уровень значимости составил 0,032. Скорректированный 
$\mathrm{R}^{2}$ составил 0,059 . Коэффициент регрессии положительный. Это означает, что увеличение количества независимых директоров в совете директоров должно привести к увеличению инвестиций в НИОКР. Причиной, возможно, является тот факт, что доля внешних директоров публичной компании, акции которой торгуются на бирже, всегда составляет либо $1 / 3$, либо $1 / 4$, что не позволяет данному показателю уловить различия в инвестициях в НИОКР. Количество же независимых директоров обычно варьируется от компании к компании. Чем выше количество внешних независимых директоров, тем выше в таких компаниях инвестиции в НИОКР. Пятая гипотеза подтверждается с небольшим изменением.

Таблица 5. Регрессия инвестиций в НИОКР от количества независимых внешних директоров

\section{Model Summary and Parameter Estimates}

Dependent Variable: R\&D investment intensity

\begin{tabular}{|l|r|r|r|r|r|r|r|}
\hline \multirow{2}{*}{ Equation } & \multicolumn{5}{|c|}{ Model Summary } & \multicolumn{2}{c|}{ Parameter Estimates } \\
\cline { 2 - 8 } & R Square & $\mathrm{F}$ & $\mathrm{df1}$ & $\mathrm{df2}$ & Sig. & Constant & b1 \\
\hline Linear & .059 & 4.769 & 1 & 76 & .032 & -.001 & .002 \\
\hline
\end{tabular}

The independent variable is Independent outside directors.

\section{Заключение}

В рамках данного исследования мы попытались выяснить, влияют ли дискреционная власть менеджмента, доля государственной собственности, доля собственности в руках менеджмента и количество независимых директоров на интенсивность инвестиций в НИОКР. В выборку были включены компании, акции которых торгуются на фондовом рынке Китая. Было обнаружено следующее:

- отрицательная зависимость между дискреционной властью менеджмента и инвестициями в НИОКР;

- квадратичная зависимость между долей менеджмента в акционерном капитале и инвестициями в НИОКР;

- положительная зависимость между количеством независимых директоров и инвестициями в НИОКР.

Эти результаты подтвердили три наши гипотезы. Однако оставшиеся две гипотезы в результате проведения эконометрического анализа данных не подтвердились.

Мы предполагали наличие отрицательной корреляции между долей государственной собственности и инвестициями в НИОКР. Компании с высокой долей государственной собственности часто являются монополистами на рынке и работают в условиях низкой конкуренции, что определяет их невысокую мотивацию к инновациям. Однако результаты тестов не подтвердили наше предположение. Возможным объяснением может быть то, что компании с высокой долей государственной собственности легче подвергаются влиянию новых общенациональных инициатив. В последние годы правительство Китая постоянно указывает на необходимость внедрения инноваций. Компании с высокой долей государственной собственности в первую очередь должны задуматься о реализации правительственных инициатив и увеличить инвестиции в НИОКР. Такой взгляд на ситуацию, а также инерционный характер инновационных процессов определяют отсутствие значимой корреляции между долей государственной собственности и инвестициями в НИОКР.

Результаты проведенных регрессий свидетельствуют об отсутствии значимой зависимости между концентрацией собственности и инвестициями в НИОКР. Мы предполагаем, что это связано с особенностями институциональных инвесторов в Китае. Институциональные инвесторы в Китае - это прежде всего государство, фондовые 
компании и множество видов инвестиционных компаний. Стратегии и интересы данных групп очень сильно различаются. Инвестиционные компании обычно представляют собой краткосрочных инвесторов, которые в первую очередь интересуются финансовыми результатами торгуемых компаний. Фондовые компании обычно держат акции в течение более долгого срока и предпочитают стабильный доход от объектов своих инвестиций. Государство является наиболее долгосрочным инвестором, чей интерес имеет комплексный характер и включает возможность получения дохода, необходимо реализации отраслевых инициатив, а также решения макроэкономических вопросов. Таким образом, одна часть институциональных инвесторов заинтересована в устойчивом развитии, а другая - в краткосрочных финансовых результатах. Степень концентрации собственности не учитывает данные различия и, таким образом, не связана с инвестициями в НИОКР.

В рамках данного исследования мы попытались понять влияние факторов корпоративного управления на интенсивность корпоративных инвестиций в инновационные проекты. Можно сказать, что улучшение в компании инновационных процессов и увеличение интенсивности инвестиций в НИОКР может быть достигнуто путем оптимизации системы корпоративного управления. В Китае относительно невысокие инвестиции в НИОКР могут быть связаны, в том числе, с высокой дискреционной властью менеджмента. В данных условиях включение акций в компенсационный пакет топменеджмента может позволить увеличить мотивацию руководства компании инвестировать в НИОКР и расширить горизонт планирования. Более того, увеличение количества независимых директоров в совете директоров также будет положительно влиять на инновационные процессы в китайских компаниях.

Исследование, о котором мы рассказали, обладает недостатками. Во-первых, ограниченность выборки не позволила нам в полном объеме выполнить задуманное. Вовторых, наблюдаемые зависимости в крупных торгующихся компаниях могут отличаться от таких же зависимостей в неторгующихся компаниях среднего и малого размера. В-третьих, мы не контролировали отраслевые характеристики и не можем с уверенностью утверждать, что полученные зависимости не определяются отраслевой спецификой. Все перечисленные недостатки дают нам возможность продолжить работу над исследованием в будущем.

\section{Список литературы}

1. Alchian A. A., Demsetz H. Production, information costs, and economic organization / American Economic Review, 1972, 62, pp. 777-795.

2.Barker III V., Mueller G. CEO characteristics and firm / R\&D spending Management Science, 2002, 48 (6), pp. 782-801.

3. Baysinger B.D., Hoskisson R.E. Diversification strategy and R\&D intensity in large multiproduct firms / Academy of Management Journal, 1989, 32, pp. 310-332.

4. Baysinger B.D., Hoskisson R.E. The composition of boards of directors and strategy control: Effects on corporate strategy / Academy of Management Review, 1990, 15, pp. 72 -87.

5. Baysinger B.D., Kosnik R.D., Turk T. A. Effects of board ownership structure on corporate R\&D strategy / Academy of Management Journal, 1991, 34, pp. 205-214.

6. Millet-Reyes B. R\&D Intensity and Financing Constraints /The Journal of Business and Economic Studies, 2004, Fall, 10 (2), p. 38.

7. Johannisson B., Lindstrom C. Firm Size and Inventive Activity / Swedish Journal of Economics, 1971, №4, 28-714814

8. Bushee B. J. Do institutional investors prefer near-term earnings over long-run value? /Contemporary Accounting Research; Summer 2001; 18, 2; ABI/INFORM Global, p. 207.

9. Bushee B. J. The influence of institutional investors on myopic R\&D investment behavior / The Accounting Review, 1998, 73, pp. 305-333.

10. David P., Hitt M. A., Gimeno J. The role of institutional investors in influencing R\&D / Academy of Management Journal, 2001, 44, pp. 144-157. 
11. Huamao Bai D.The Impact of R\&D and Institutions on the Performance of Chinese Industry / The Faculty of the Graduate School of International Economics and Finance Brandies University, May 2003.

12. Gilson R.J., Kraakman R. Reinventing the outside director: An agenda for institutional investors / Stanford Law Review, 1991, 43, pp. 863-906.

13 Graves S.B., Waddock S.A. Institutional ownership and control: Implications for longterm corporate strategy / Academy of Management Executive, 1990, 4(1), pp. 75-83.

14. Graves S.B. Institutional ownership and corporate R\&D in the computer industry / Academy of Management Journal, 1988, 31, pp. 417-428.

15. Tassey G. R\&D investment trends: U.S. needs more high-tech /Research Technology Management, 2003, Mar/Apr: 9.

16. Hoskisson R E., Hitt M. A., Johnson R. A., Grossman W. Conflicting voice: The effects of institutional ownership heterogeneity and internal governance on corporate innovation strategies / Academy of Management Journal, 2002, 45, pp. 697-716.

17. Hoskisson Robert E. Hitt Michael A. Strategic control systems and relative R\&D investment in large multiproduct firms / Strategic Management Journal, 1988, Nov/Dec, p. 605.

.18. Hay D. A., Morris D.J. Industrial economics: Theory and evidence / Oxford, U.K.: Oxford University Press, 1979.

19. Hill C.W.L., Snell S.A. External control, corporate strategy, and firm performance in research-intensive industries /Strategy Management Journal, 1988, 9, pp. 605-621.

20. Hill C.W.L., Hansen G. S. Institutional holdings and corporate R\&D intensity in researchintensive industries / Academy of Management Best Paper Proceedings, 1989, pp. 17-21.

21. Kochhar R., David P. Institutional investors and firm innovation: A test of competing hypotheses / Strategic Management Journal, 1996, 17, pp. 73-84.

22. Li. Y. G. The discretionary power of manager in corporate governance [D] / Xi'an: Xian Jiaotong University, 2002, pp.21-44.

23. Luoma P., Goodstein J. Stakeholders and corporate boards: institutional influences on board composition and structure / Academy of Management Journal, 1999, 42, pp. 553-563. 